\title{
Experimental and Numerical Investigation into the Thermal Effects of Direct Fuel Injection in $\mathrm{HCCl}$ Engine
}

\author{
Jacek Hunicz $^{1}$, Michal S. Geca ${ }^{1}$, Maciej Mikulski ${ }^{2}$, Robert Tyda ${ }^{1}$ \\ ${ }^{1}$ Lublin University of Technology, Faculty of Mechanical Engineering \\ Nadbystrzycka 36, 20-618 Lublin, Poland \\ J.hunicz@ pollub.pl; Michal.geca@pollub.pl; Rtyda@onet.pl \\ ${ }^{2}$ TNO Automotive \\ Automotive Campus 30, 5708 JZ, Helmond, Netherlands \\ Maciej.mikulski@tno.nl
}

\begin{abstract}
In this paper Homogeneous Charge Compression Ignition (HCCI) engine utilising Negative Valve Overlap (NVO) injection of gasoline was subjected to combined experimental and numerical investigation. The thermal effects of direct fuel injection during NVO and its impact on intake process as well as main event compression temperature histories were investigated in this study. The research was performed for a constant speed of $1500 \mathrm{rev} / \mathrm{min}$ and two main event excess air ratios (stoichiometric $\lambda=1$ and lean $\lambda=1.2$ ). Recorded in-cylinder pressure signal served as the basis of numerical calculations performed in AVL-BOOST software. It was shown that NVO injection timing to some extent can be used as a measure to control combustion phasing. Injection timing influenced combustion phasing through changing the gasoline residence time and temperature of trapped exhaust gasses during the NVO period. At the same time important correlations between cylinder thermal conditions in NVO and intake valve flow were identified.
\end{abstract}

Keywords: HCCI, direct injection, negative valve overlap, gas exchange

\section{Introduction}

Homogeneous Charge Compression Ignition is a novel combustion technology which enables significant reduction of fuel consumption and nitrogen oxides $\left(\mathrm{NO}_{\mathrm{X}}\right)$ emission at low and medium engine load range. High thermal efficiency of HCCI is achieved because heat release process is quick in comparison with spark ignition combustion. Additionally, control of engine load via excess air and/or exhaust gas re-circulation reduces pumping losses. Auto-ignition of the combustible mixture in several locations in the combustion chamber and high fuel dilution result in low temperature combustion, which produce extremely low $\mathrm{NO}_{\mathrm{X}}$ concentrations in exhaust gas [1].

To promote auto-ignition of gasoline-based combustible mixture, temperature at the end of compression must be increased in comparison to the values achievable in spark ignition engines. Thus additional energy must be provided to the cylinder. Among different techniques one promising solution in using internal gas re-circulation realized using negative valve overlap (NVO) strategy. This valve timing strategy relies on early closing of exhaust valve and late opening of intake valve, which results in exhaust gas trapping inside a cylinder [2, 3].

To obtain engine operation in the HCCI mode it is necessary to achieve proper in-cylinder temperature at the end of compression process. However, it should be noted that in engines operated in NVO direct control of temperature inside the cylinder is not attainable. The compression temperature histories result from the amount of fresh air and its temperature, the amount of trapped residuals and the exhaust temperature itself, engine thermal state, heat losses etc. [4]. Additionally, in engines with direct fuel injection, the heat of fuel phase change, possible partial fuel oxidation before main event combustion, and finally, possible endothermic fuel reforming also have significant effect $[5,6]$.

The thermal effects of direct fuel injection during NVO and its impact on intake process as well as main event compression temperature histories were investigated in this study. The aim of the current investigations is to understand complex relationships between fuelling strategy, gas exchange process and main event combustion. 


\section{Experimental facility and data analysis}

The single-cylinder research engine specified in Table 1 was installed on a test bench equipped with a DC dynamometer. The engine was equipped with a fully variable valvetrain with independent adjustment of valves lifts and timings. The valves lifts were adjusted with the hydraulic mechanism described in details in ref. [7]. The fully variable valvetrain allowed the authors to obtain internal exhaust gas re-circulation using the NVO technique.

Table 1: Research engine configuration (all crank angle data are in orientation as in Fig. 1).

\begin{tabular}{|l|l|}
\hline Displaced volume & $498.5 \mathrm{~cm}^{3}$ \\
\hline Bore & $84 \mathrm{~mm}$ \\
\hline Stroke & $90 \mathrm{~mm}$ \\
\hline Compression ratio & 11.7 \\
\hline No of valves & 3 \\
\hline Intake valve opening (IVO) timing & $87^{\circ}$ \\
\hline Intake valve closing (IVC) timing & $217^{\circ}$ \\
\hline Intake valve lift & $2.8 \mathrm{~mm}$ \\
\hline Exhaust valve opening (IVO) timing & $515^{\circ}$ \\
\hline Exhaust valve closing (IVC) timing & $-86^{\circ}$ \\
\hline Exhaust valve lift & 2.4 mm \\
\hline Fuel injector & Solenoid actuated swirl type \\
\hline
\end{tabular}

Fuel was introduced directly into the cylinder using a side-mounted, single-stream swirl-type injector. The combustion chamber design and injector characteristics were thoroughly described in ref. [7]. The engine control system was based on in-house PC software connected with a real-time timing module to govern injection timings and durations as well as spark generation. However, the ignition circuit was switched off in the experiments; it was used exclusively for setting the engine to the HCCI mode. The engine test bench was equipped with all necessary measurement and control instruments. Fuel consumption was measured using a fuel balance and intake air flow was measured with a thermal mass flow meter. The engine was also equipped with a set of pressure and temperature transducers in order to control the thermodynamic conditions of all media; intake, exhaust, cooling liquid, etc. In-cylinder pressure was measured with the use of a miniature pressure transducer installed directly in the engine head. Pressure and other crank angle based parameters were recorded with a constant angular resolution of $0.1^{\circ}$ for 100 consecutive engine cycles and ensemble averaged. In-cylinder temperature and flows through the valves were computed using 1-dimensional model AVL-BOOST, where measured pressure was utilized as boundary condition. The engine model was validated using average air flow and exhaust temperature.

\section{Experimental conditions and procedure}

The engine was fuelled with commercial gasoline $95 \mathrm{RON}$. The experiments were conducted at one crankshaft rotational speed of $1500 \mathrm{rev} / \mathrm{min}$. The cooling liquid temperature at the engine outlet was kept constant at $87{ }^{\circ} \mathrm{C} \pm 1$. The engine was naturally aspirated and the intake air temperature was kept at the level of about $40{ }^{\circ} \mathrm{C}$. Fuel was introduced into the cylinder during the exhaust re-compression at variable start of injection (SOI) timing. In order to provide different amounts of oxygen in trapped residuals, which affected thermal effect of fuel oxidation, two main event excess air ratios $(\lambda)$ were applied; stoichiometric mixture $(\lambda=1)$ and lean mixture $(\lambda=1.2)$. Set values of excess air were maintained via corrections of the mass of fuel injected. Duration of fuel injection was approximately $12^{\circ}$ of crank angle at $\lambda=1$, and $9 \circ$ at $\lambda=1.2$.

\section{Results and discussion}

Figure 1 shows measured in cylinder pressure curves. Crank angle $-180^{\circ}$ is a bottom piston dead centre (BDC) at the beginning of exhaust stroke, angle $0^{\circ}$ is piston top dead centre (TDC) during exhaust recompression, whereas $360^{\circ}$ is TDC during the main event (start of power stroke). It can be noted from Fig. 1a that SOI timing had significant effect on both 
NVO peak pressure and combustion pressure during the main event. The later the SOI, the higher peak NVO pressure was achieved. It is plausible, as heat consumption for fuel phase change reduced temperature, as shown in Fig. 3a, and reduced resulting pressure. In contrast, for lean mixture $(\lambda=1.2)$ recompression pressure curves were nearly the same, as shown in Fig. 1b, whereas there were differences in NVO temperature, as shown on Fig. 2b. This discrepancy between two analysed cases resulted from variable amounts of trapped residuals and heat release during NVO.

Comparison of Figures $2 \mathrm{a}$ and $2 \mathrm{~b}$ revealed that peak NVO temperatures were at similar level for two applied mixture strengths, whereas significant differences in EVC temperatures were observed. For stoichiometric mixture EVC temperature was approximately $100 \mathrm{~K}$ higher than for the lean mixture $(\lambda=1.2)$. Variability in EVC temperature resulted directly from the main event combustion where leaner mixture combustion produced over $300 \mathrm{~K}$ lower peak temperature. However, lean mixture enhanced heat release during the NVO period, thus increasing NVO temperature.
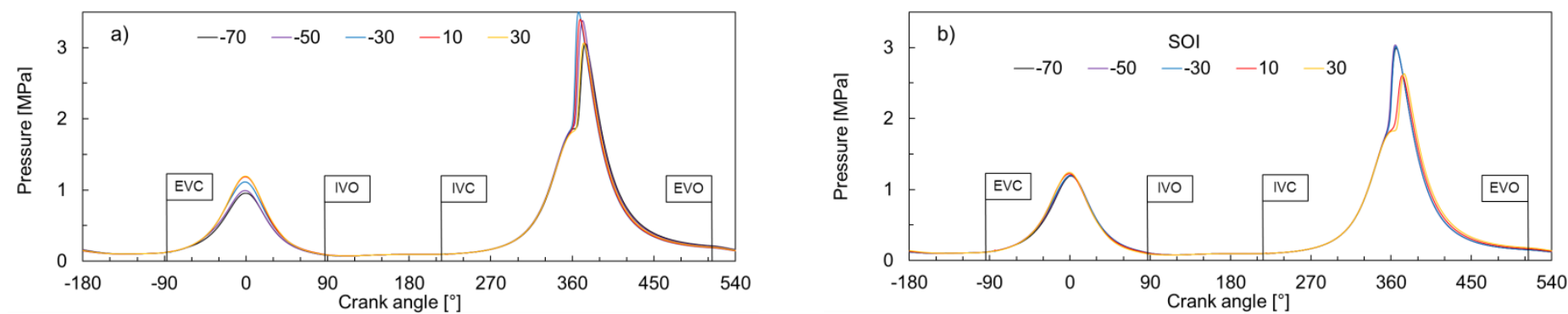

Fig. 1: Measured in-cylinder pressure for variable SOI; a) $\lambda=1.0$, b) $\lambda=1.2$.
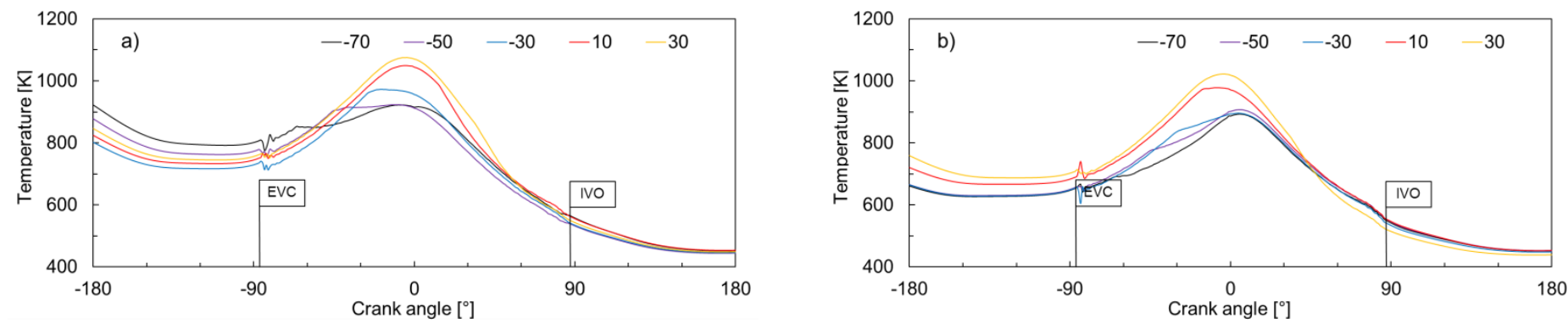

Fig. 2: Computed in-cylinder temperature during gas exchange and NVO for variable SOI; a) $\lambda=1.0$, b) $\lambda=1.2$.
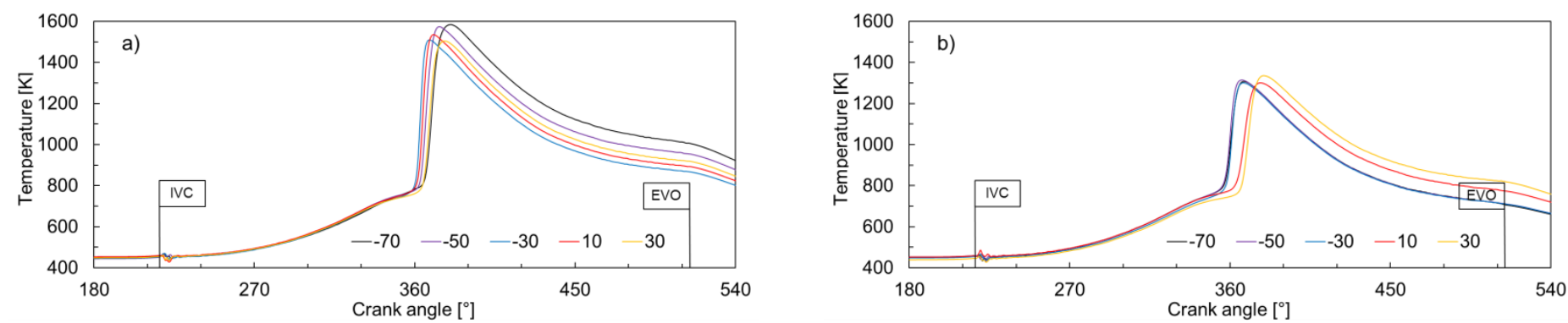

Fig. 3: Computed in-cylinder temperature during main event for variable SOI; a) $\lambda=1.0, b) \lambda=1.2$.
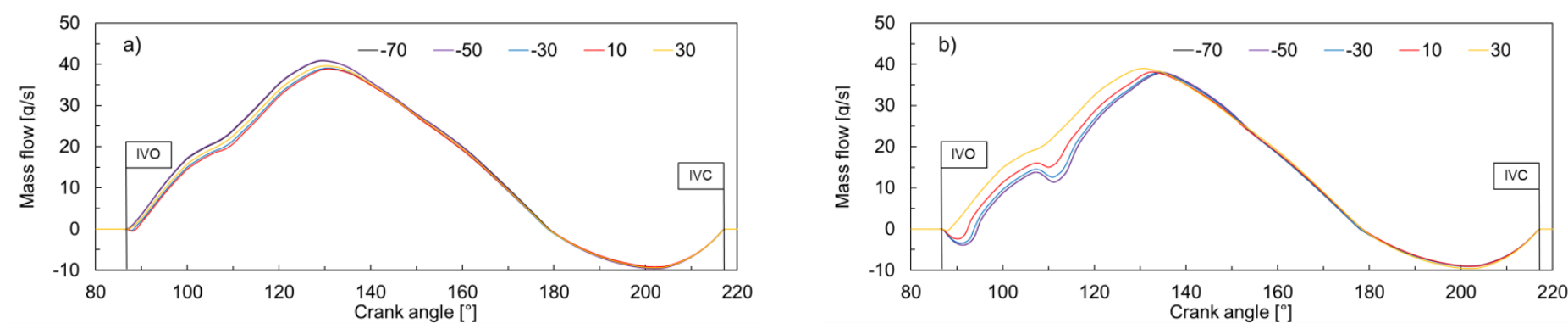
Fig. 4: Computed mass flow rate during intake process for variable SOI; a) $\lambda=1.0, \mathrm{~b}) \lambda=1.2$.

Comparison of combustion timings and temperature histories shows effects of both gas temperature and mixture reactivity on auto-ignition. Later SOI in the NVO period generally caused retarded SOC in the main event without significant evidence in temperature. This trend was clearly visible in Fig. 1b. Shifting SOI from $-70^{\circ}$ to $-30^{\circ}$ was associated with only slightly prolonged start of combustion (SOC) (in a range of $2^{\circ}$ ), whereas introducing SOIs after TDC $\left(\mathrm{SOI}=10^{\circ}\right.$ ) caused a step shift in ignition after main event TDC. This proves that residual times have dominating effect on production of auto-ignition promoting species, over the residual gas temperature. This phenomena was confirmed for the stoichiometric case where similar trend was observed for SOIs in range from $-50^{\circ}$ to $30^{\circ}$ (Fig. 1a and Fig. 2a). Note that SOI $=-70^{\circ}$ case manifested an exception from this trend resulting in significantly retarded SOC despite highest EVC temperature and longest residual times. This can be explained by results on Fig. 2a, which showed large temperature drop after early injection events. This temperature drop was associated to both - additional (cold) mass introduced to the system and gasoline evaporative cooling effect which was much more significant for stoichiometric cases compared to lean mixture (Fig. 2b). The NVO temperature profile in Fig. 2a shows that for $\mathrm{SOI}=-70^{\circ}$, relative time of gasoline residence in high temperature, sufficient to trigger pre-ignition mechanisms, was the shortest of all analysed cases.

Lower in-cylinder pressures due to excessive exhaust gas cooling by evaporating gasoline in stoichiometric SOI $=-70^{\circ}$ case resulted in considerably higher intake mass flow rates (Fig. 3a). This caused further dilution of the mixture and consequently contributed to prolonged main event SOC. Differences in intake flows where considerably more significant for lean cases, as shown in Fig 3b. Also here the correlation between retarded combustion and higher intake flow rates was clearly recognized. Note that in all analysed fuelling scenarios NVO phenomena had a considerable effect solely on early stage of intake process. The flow rates in a later stage of intake process as well as observed large backflows after piston bottom dead centre were nearly constant for the analysed cases.

\section{Conclusion}

The work revealed the sensitivity of combustion process on gasoline SOI during NVO in HCCI engine. This strategy can be used to achieve control over combustion phasing, keeping the vast advantages of using homogeneous mixture during main combustion event. The phasing control was found difficult due to observed nonlinearities in SOI-NVO / SOCmain event trends. The effect was strongly coupled with both NVO thermal conditions and intake flow rate, proving that combined valve timing and SOI control is essential for providing efficient HCCI mode operation.

\section{Acknowledgements}

The research was funded by the National Science Centre, Poland under grant No. 2015/17/B/ST8/03279. The authors wish to thank AVL List GmbH for making simulation software available within a framework of AVL University Partnership Program.

\section{References}

[1] M. Yao, Z. Zheng, H. Liu, "Progress and recent trends in homogeneous charge compression ignition (HCCI) engines," Prog Energy Combust Sci, vol. 35, no. 5, pp. 398-437, 2009.

[2] J. Lavy, J. Ch. Dabadie, Ch. Angelberger, et al., „Innovative ultra-low NOX controlled auto-ignition combustion process for gasoline engines: the 4-SPACE project," SAE Technical Paper 2000-01-1837, 2000.

[3] A. Oakley, H. Zhao, N. Ladommatos, et al., "Experimental studies on controlled auto-ignition (CAI) combustion of gasoline in a 4-stroke engine," SAE Technical Paper 2001-01-1030, 2001.

[4] L. M. Olesky, G. A. Lavoie, D. N. Assanis, et al., "The effects of diluent composition on the rates of HCCI and spark assisted compression ignition combustion," Appl Energy, vol. 124, pp. 186-198, 2014.

[5] T. K. Lee, H. H. Song, "Computational study on recompression reaction of the pilot-injected fuel during negative valve overlap by using a cycle-coupled, isooctane-fueled homogeneous charge compression ignition engine model," Int J Engine Res, vol. 15, pp. 830-849, 2014.

[6] B. Wolk, I. Ekoto, W.F. Northrop, et al., "Detailed speciation and reactivity characterization of fuel-specific incylinder reforming products and the associated impact on engine performance," Fuel, vol. 185, pp. 348-361, 2016.

[7] J. Hunicz, M. S. Geca, P. Kordos, H. Komsta, "An experimental study on a boosted gasoline HCCI engine under different direct fuel injection strategies," Exp Therm Fluid Sci, vol. 62, pp. 151-163, 2015. 